\title{
MRI of the Knee: What Do We Miss?
}

\author{
Claus Simpfendorfer $\cdot$ Joshua Polster
}

Published online: 20 February 2014

(c) Springer Science+Business Media New York 2014

\begin{abstract}
Magnetic resonance (MR) imaging is a commonly used tool when evaluating patients with acute knee injury or chronic knee pain. Although it has shown excellent accuracy in diagnosing knee pathology, there remain many potential pitfalls and missed lesions. These can be secondary to inherent technical limitations or artifacts related to MR. Also subtle pathology can be overlooked, and anatomic structures and associated variants can be misinterpreted as tears. In this article, we will review some of the more common misses or pitfalls that occur in the setting of sport-related injuries.
\end{abstract}

Keywords MRI $\cdot$ Knee $\cdot$ Meniscus $\cdot$ Cruciate ligaments

\section{Introduction}

Since its introduction, magnetic resonance (MR) imaging has quickly become the gold standard for noninvasive evaluation of the knee [1]. Thanks to its excellent soft tissue contrast, high spatial resolution and multiplanar images, MR provides an accurate depiction of the anatomy and associated intra- and extra-articular pathology. As a result, MR has become a valuable tool with a significant impact on patient care and treatment. In the setting of acute knee trauma, MR has been shown to change the initial diagnosis and subsequent therapy in over $50 \%$ of cases

This article is part of the Topical Collection on Imaging of Sports Injuries.

C. Simpfendorfer $(\bowtie) \cdot$ J. Polster

Cleveland Clinic, A21 9500 Euclid Avenue, Cleveland,

OH 44195, USA

e-mail: simpfec2@ccf.org
[2]. For this reason, MR is often used in conjunction with the clinical exam for preoperative evaluation and planning. Despite these strengths and advances in coil and MR technology, there remain many potential pitfalls and missed pathologies. These can be secondary to technical artifacts or limitations, anatomic variations, subtle pathology that is overlooked and misinterpretation. This article will focus on the more common misses or pitfalls that occur in the setting of sport-related injuries.

\section{Menisci}

The menisci are critical structures for normal knee mechanics. Attempts at meniscal preservation have led to advanced meniscal repair techniques with improved longterm outcomes [3]. Successful repair is dependent on the tear location and pattern-with peripheral, longitudinal tears having the best outcome [4]. Despite MR having a high sensitivity and specificity in diagnosing meniscal tears of 88 and $94 \%$, respectively, we continue to overcall or undercall tears [5-7]. The increased use of 3-Tesla (3-T) MR scanners in clinical practice has not demonstrated significant improvements in diagnostic accuracy for meniscal tears when compared to 1.5 Tesla $(1.5 \mathrm{~T})[8,9]$.

Overcalling tears can be secondary to another pathology that causes signal alterations in the meniscus. Underlying degenerative changes, such as intrasubstance or myxoid degeneration in older patients and residual vascularity within the periphery of the meniscus in younger patients, can result in increased signal within the meniscus $[10,11]$. In the setting of trauma, increased signal within the meniscus can be secondary to meniscal contusion. [12] Although these findings can be mistaken for a tear, careful evaluation should demonstrate the absence of disruption or 
communication with the articular surface. Chondrocalcinosis also results in increased signal within the meniscus mimicking myxoid degeneration and possible tears. In the setting of chondrocalcinosis, MRI shows a significant decrease in both, sensitivity and specificity to 72 and $78 \%$, respectively [13].

Understanding the meniscal anatomy and its variations can help avoid misinterpretation of normal structures, which may mimic a tear. Although the menisci are normally low signal, the anterior root of the lateral meniscus can have a fissured or striated appearance secondary to decreased density of the collagen fibers, interposed fibrofatty tissue or interposed fibers of the anterior cruciate ligament (Fig. 1) [14]. The transverse ligament, which

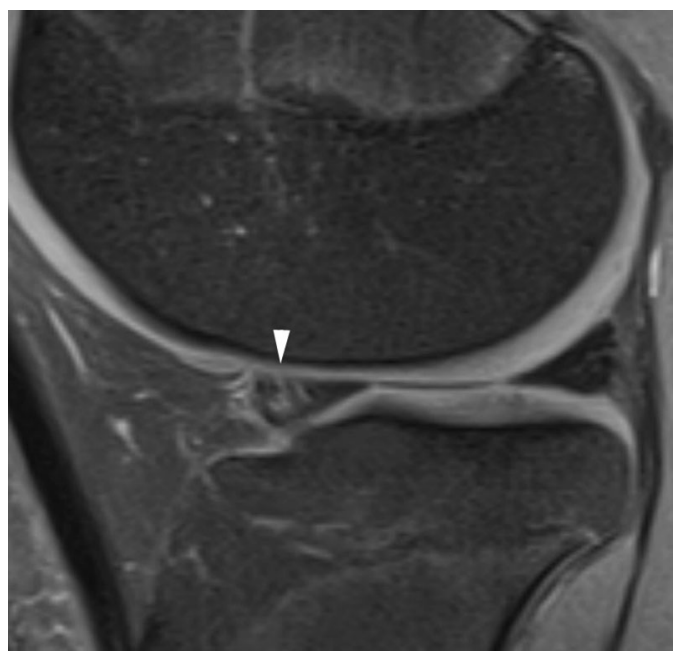

Fig. 1 Sagittal PD-weighted fat-suppressed images of a 17-year-old male show the striated appearance of the anterior horn of the lateral meniscus (arrowhead), which can be mistaken for a tear attaches to the anterior horns of the menisci, can be mistaken for a tear (Fig. 2) [15]. Similarly, the meniscofemoral ligaments, the popliteomeniscal fascicles and popliteus tendon can all resemble peripheral tears in the posterior horn of the lateral meniscus (Fig. 3) [16]. The oblique meniscomeniscal ligament, which connects the anterior horn of one meniscus to the posterior horn of the contralateral meniscus, only occurs in $1-4 \%$ of the population and can resemble a displaced meniscal fragment within the intercondylar notch (Fig. 4) [17]. Being aware of these normal anatomic structures can help avoid misinterpretation.

Overlooked meniscal tears involve the less commonly seen vertical longitudinal tears and radial tears, which

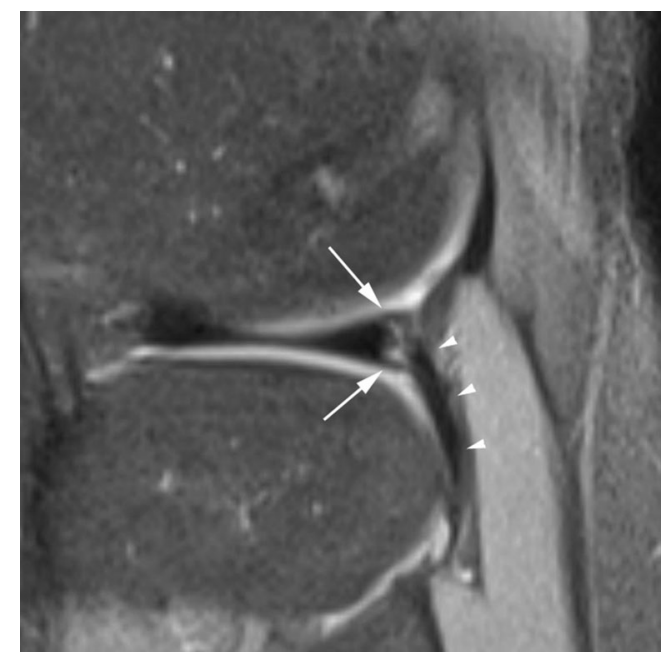

Fig. 3 Sagittal PD-weighted fat-suppressed image shows linear increased signal (arrows) between the posterior horn of the lateral meniscus and popliteus tendon (arrowheads), which can mimic a tear
Fig. 2 a Sagittal PD-weighted image and $\mathbf{b}$ coronal T1weighted image demonstrate the transverse ligament (arrowheads). Linear increased signal (arrow) between the transverse ligament and anterior horn of the lateral meniscus can mimic a tear
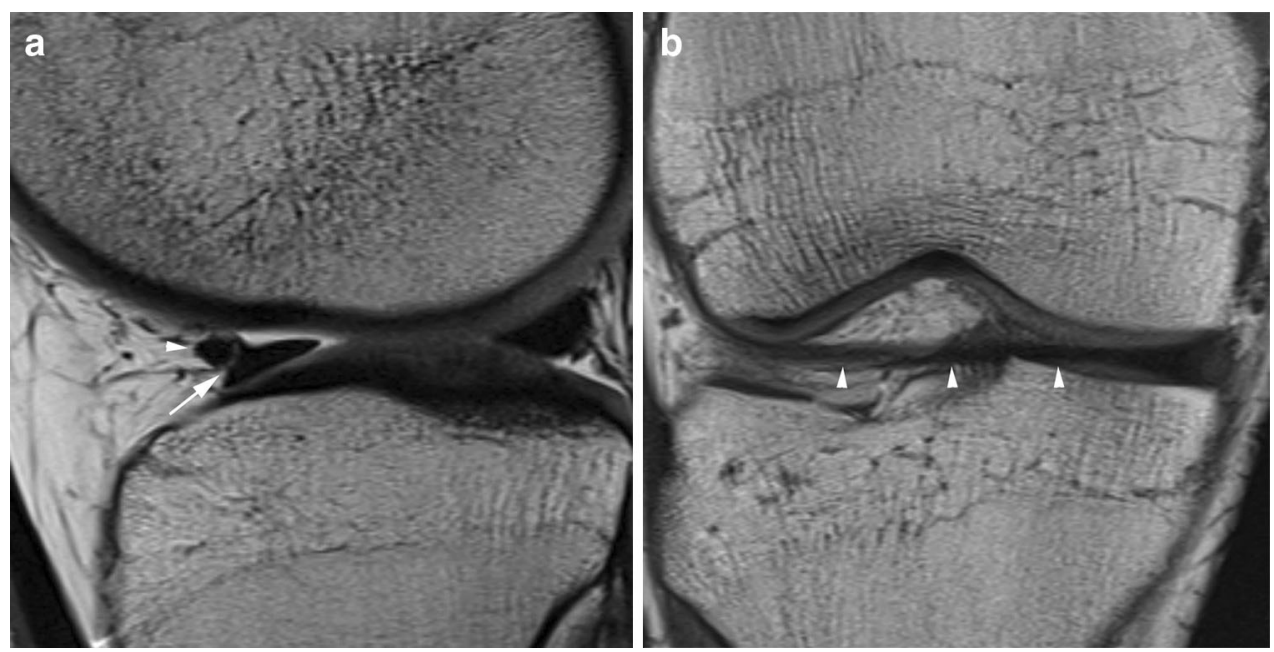

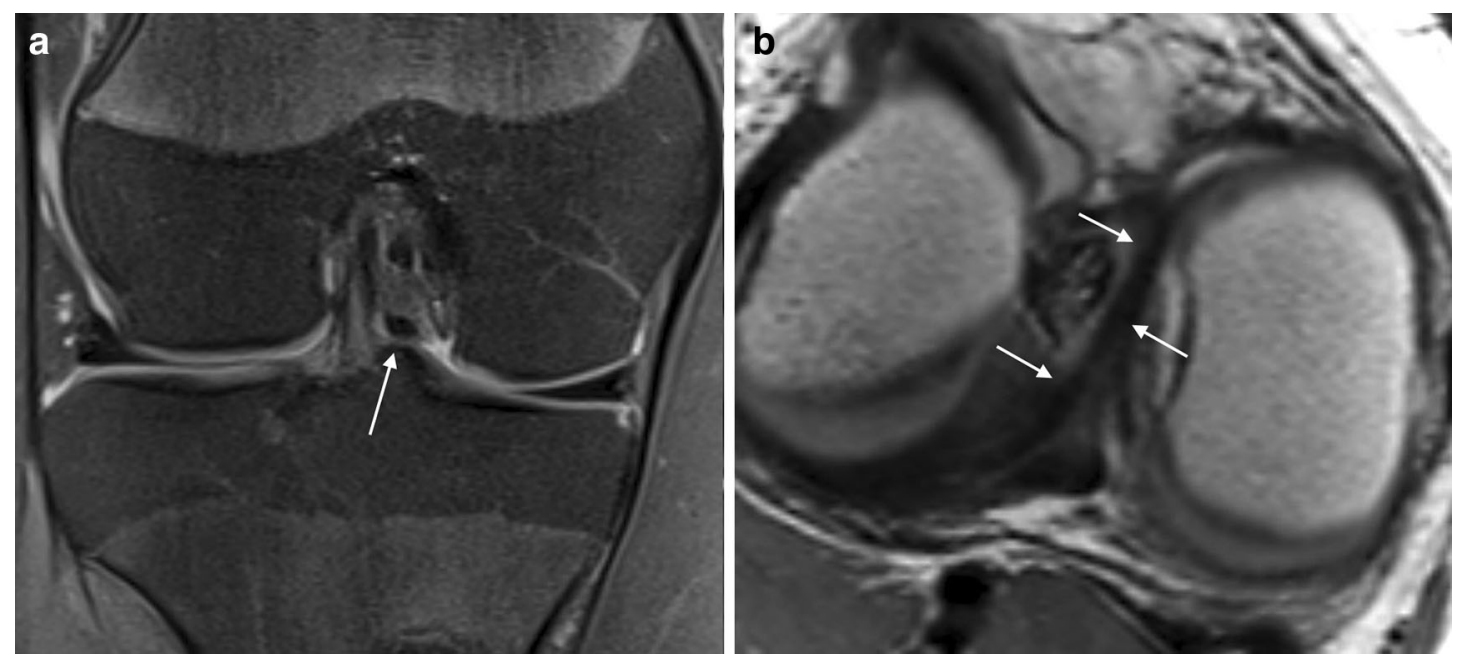

Fig. 4 a Coronal T2-weighted fat-suppressed image and $\mathbf{b}$ axial PD-weighted image demonstrate the uncommon oblique meniscomeniscal ligament (arrows), which can resemble a displaced meniscal fragment within the intercondylar notch

comprise about 10 and $15 \%$ of meniscal tears, respectively [18]. The longitudinal tears (Fig. 5) appear to be the most challenging to diagnose and tend to occur in the setting of significant knee injury [19]. A review by De Smet et al. [20] found that missed tears were typically located in the posterior root or posterior horn. Sixty percent of the missed tears, identified retrospectively, were peripheral longitudinal tears in the setting of an ACL injury (Fig. 6). Closer scrutiny of the posterior horns and roots of the menisci should be performed, especially in the setting of ACL injury. Longitudinal tears are not only missed more frequently, but are also a cause of false-positive exams. In the setting of an anterior cruciate ligament tear, the PPV for longitudinal tears drops from 96-78\% [20]. Spontaneous healing of peripheral longitudinal tears may account for some false-positive MR exams (Fig. 7) [21].
Radial tears and meniscal root tears are easily overlooked on MR as they are often visible on a single image only and are the exception to the often-used two-slice touch rule (Fig. 8) [22, 23]. These tend to be degenerative in origin in the medial meniscus and trauma-related in the lateral meniscus [22]. Tears can appear as truncation of the meniscus, a cleft or "ghost" meniscus and are associated with meniscal extrusion and accelerated osteoarthritis (Fig. 9) [18, 23, 24]. Thin axial slices on $3 \mathrm{~T}$ have been shown to be helpful in diagnosis since the conspicuity of the tear is better with decreased slice thickness (Fig. 10) [25•, 26].

The most common tears are horizontal or oblique tears, which can be missed when there is a flipped or displaced meniscal fragment. This is because the non-displaced portion of the meniscus may have a normal appearance
Fig. 5 A 23-year-old male with an underlying ACL tear. a Sagittal PD-weighted image shows a peripheral longitudinal tear (arrows) in the posterior horn of the medial meniscus, which is more conspicuous on the b sagittal T2-weighted fatsuppressed image
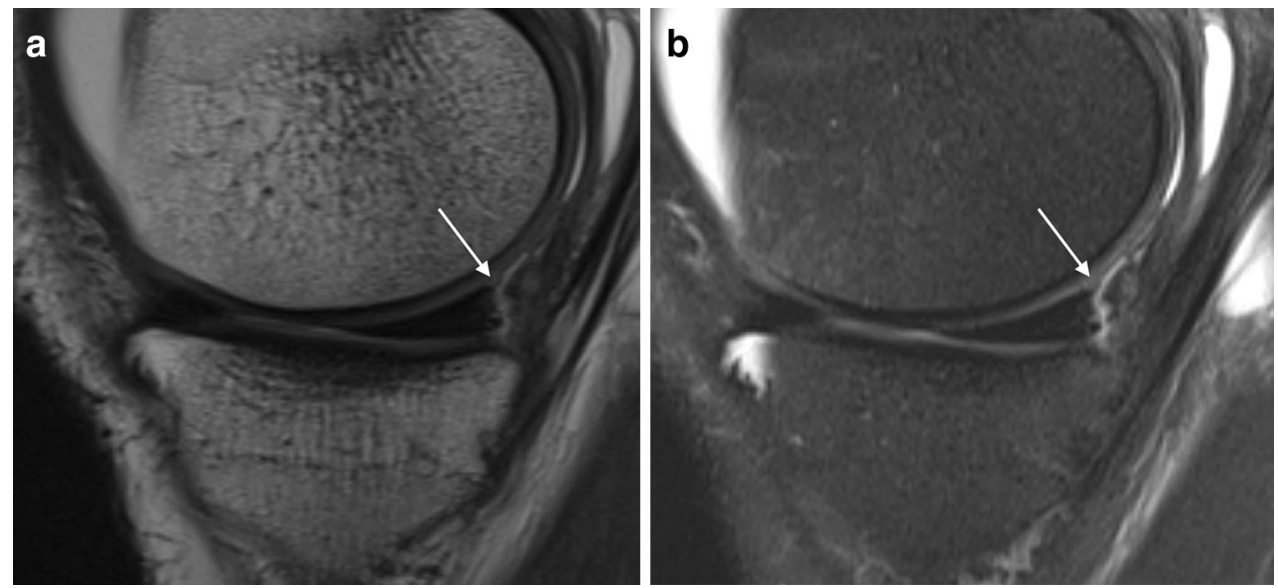

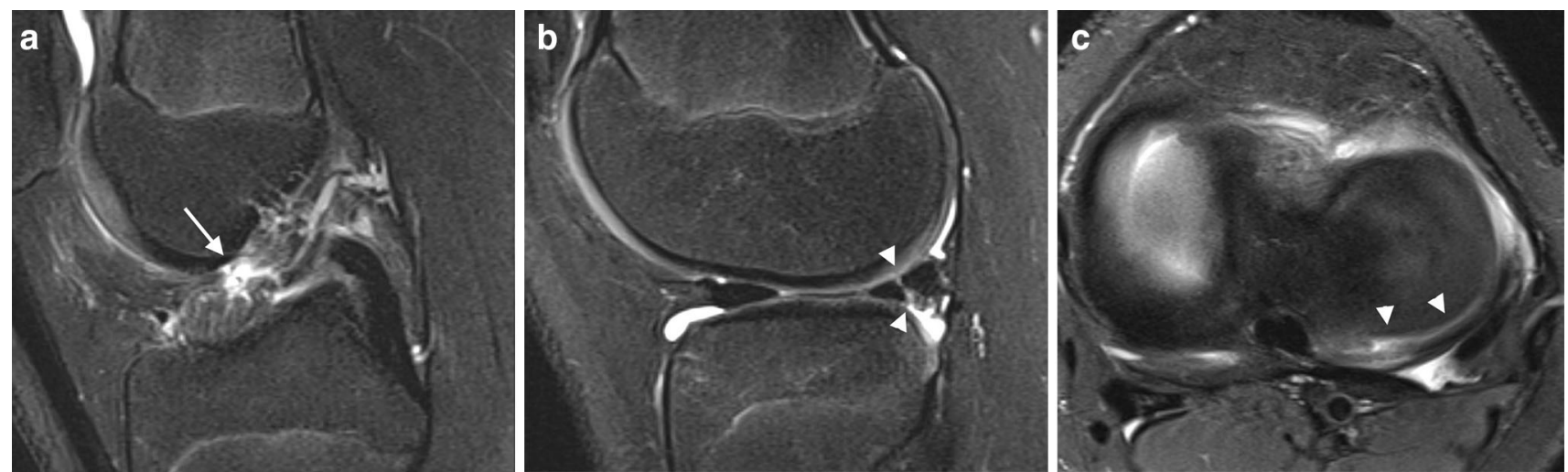

Fig. 6 A 15-year-old male injured playing soccer. a Sagittal PDweighted fat-suppressed image demonstrates a complete ACL tear (arrow). b Sagittal PD-weighted fat-suppressed image and $\mathbf{c}$ axial T2- weighted fat-suppressed image show a longitudinal tear of the posterior horn of the lateral meniscus (arrowheads)
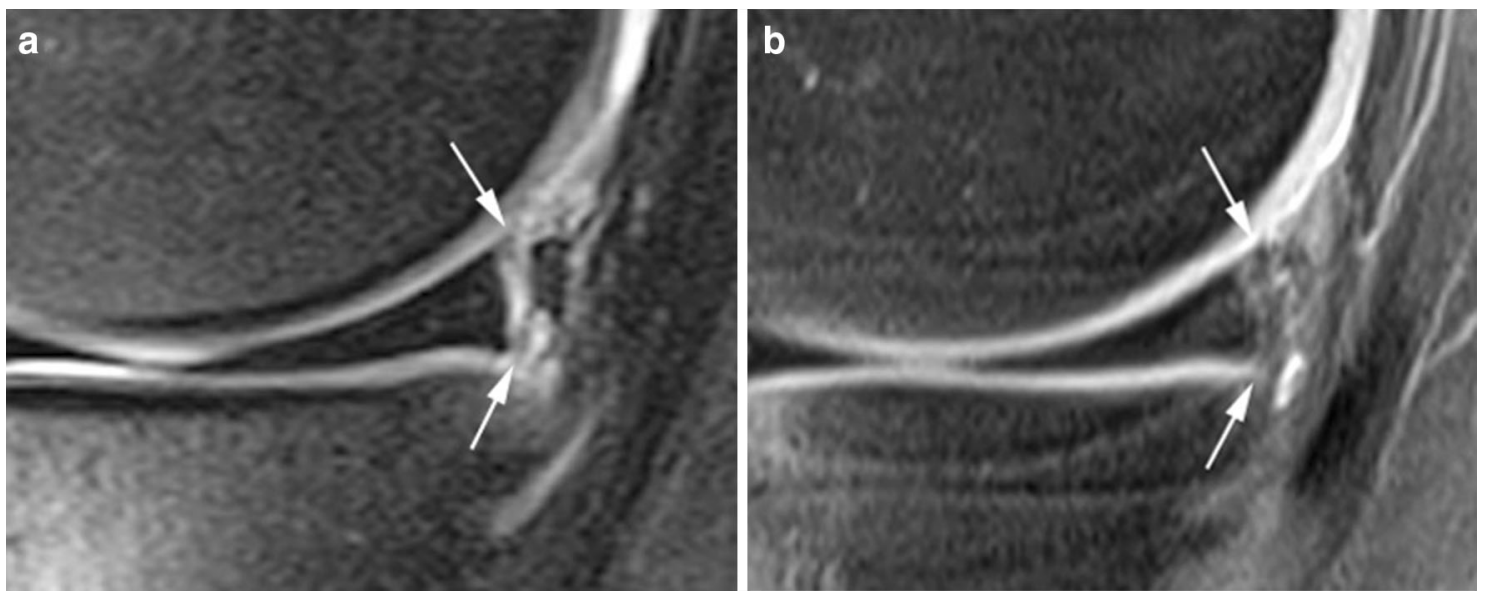

Fig. 7 Sagittal PD-weighted fat-suppressed images of a 18-year-old male with an ACL tear and reconstruction show interval healing of a peripheral longitudinal tear of the posterior horn of themedial meniscus (arrows) at the time of initial injury (a) and 3-month follow-up (b)

other than decreased size or abnormal contour. The most common locations for displaced fragments are the posterior joint space adjacent to the posterior cruciate ligament (PCL), as well as the superior and inferior recesses adjacent to the bodies of the meniscus (Fig. 11) [27]. It is of clinical importance to identify displaced meniscal fragments because they can be missed during arthroscopy and can result in persistent symptoms if not removed [28].

\section{Meniscocapsular separation}

Meniscocapsular separation is often missed, even by experienced MSK radiologists. Subtle signs of meniscocapsular separation include meniscal displacement, peripheral meniscal corner tears, increased perimeniscal edema, and fluid deep to the MCL [29]. However, these signs are nonspecific and when present the positive

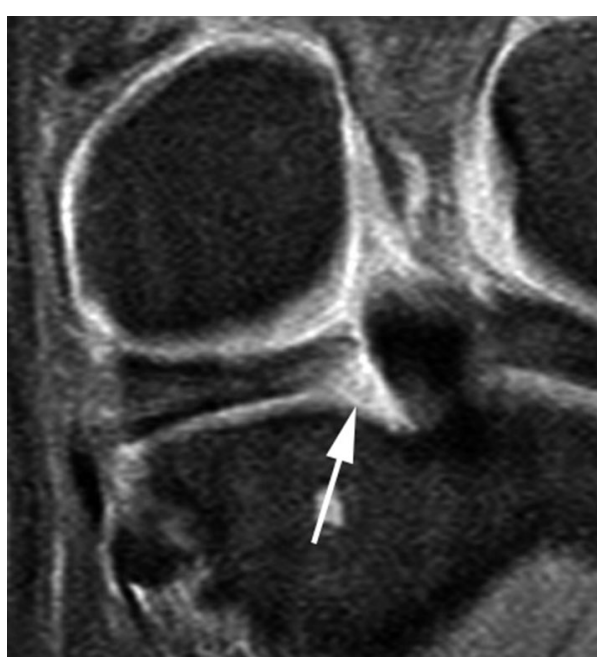

Fig. 8 Coronal T2-weighted fat-suppressed image shows a radial tear posterior to the root of the medial meniscus (arrow) 


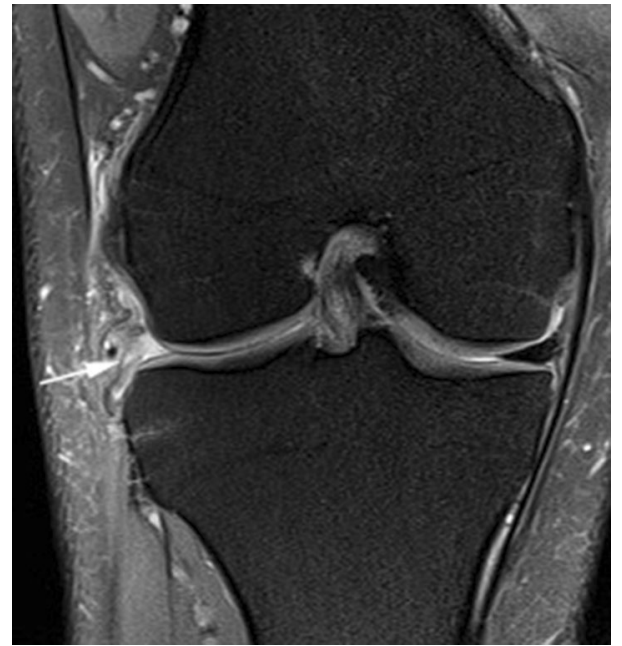

Fig. 9 Coronal PD-weighted fat-suppressed image shows absent body of the lateral meniscus or "ghost" meniscus (arrow) consistent with a radial tear

predictive value for a meniscocapsular separation is only $9 \%$ for the medial meniscus and $13 \%$ for the lateral meniscus [30]. A fatty lamellar structure is frequently located between the medial collateral ligament (MLC) and the adjacent medial meniscus. The resulting increased signal on $\mathrm{T} 2$ or proton density sequences can be misinterpreted as a meniscocapsular separation. The use of fat suppression or non-fat-suppressed $\mathrm{T} 1$ can easily distinguish between the two. The normally occurring MCL bursa can also mimic a meniscocapsular separation when filled with fluid. This bursa is present in approximately $90 \%$ of individuals based on cadaveric studies and can be fluid filled in cases of medial tibiofemoral osteoarthritis [31]. Additionally, the evaluation of meniscocapsular tears can be complicated by the previously mentioned peripheral vascularity of the

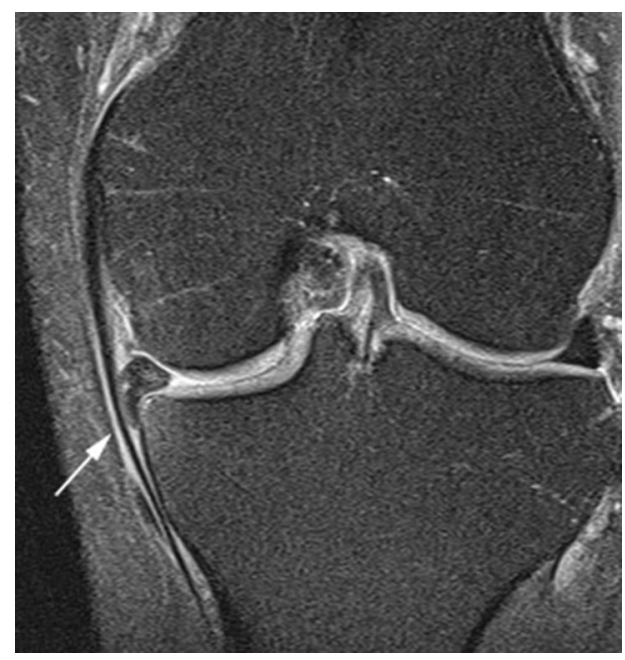

Fig. 11 Coronal PD-weighted fat-suppressed image shows a medial meniscal tear with a fragment flipped into the inferior recess (arrow)

meniscus, the so-called red zone, as well as by the presence of physiologic recesses.

\section{Cruciate Ligaments}

MR has excellent sensitivity and specificity in evaluating acute complete tears of the cruciate ligaments, but is more limited with partial or chronic tears. Partial tears, which are difficult to diagnose on physical exam, comprise approximately $10-16 \%$ of all ACL tears [32,33]. Although partial tears do not require immediate surgical treatment, diagnosis is important as a significant number of partial tears progress to complete deficiency of the ACL with resulting ligamentous laxity $[34,35]$. The diagnosis of partial tears is complicated by the striated appearance of a normal ACL,
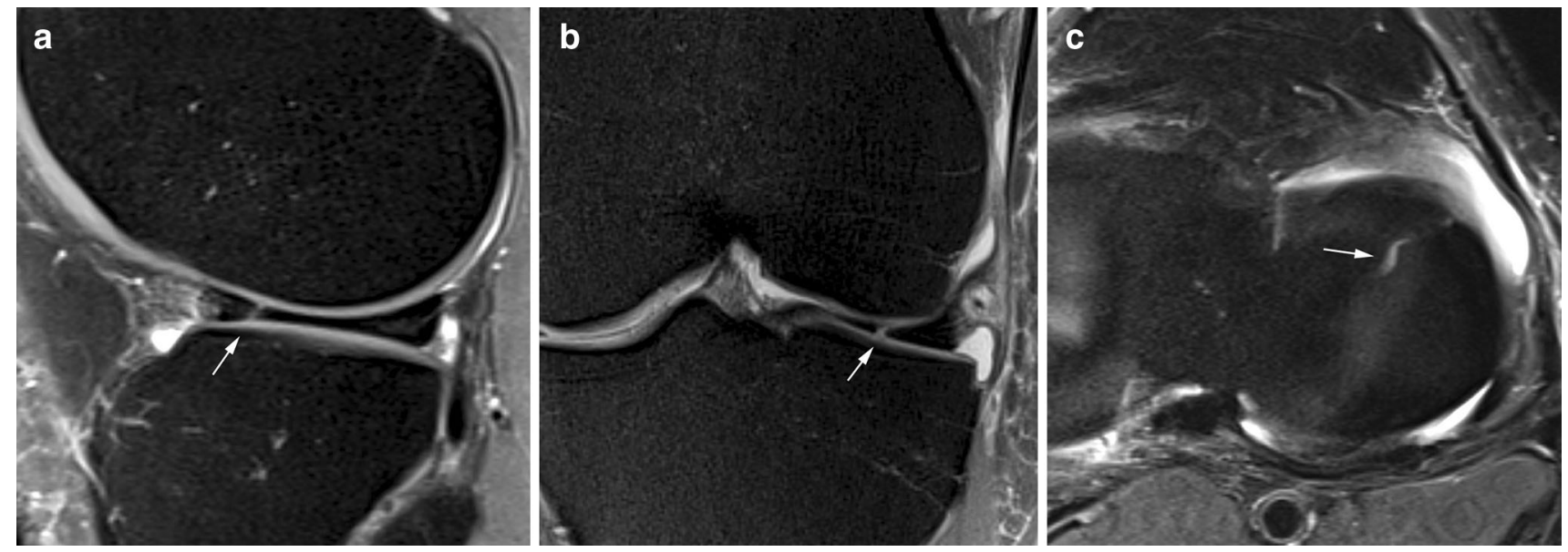

Fig. 10 a Sagittal and $\mathbf{b}$ coronal PD-weighted fat-suppressed images and $\mathbf{c}$ axial T2-weighted fat-suppressed images of a 22-year-old male show a radial tear (arrows) of the anterior horn of the lateral meniscus 
Fig. 12 A 36-year-old male with mucinous degeneration of the ACL. a Sagittal and b coronal PD-weighted fatsuppressed images show increased signal and thickening of the intact ACL
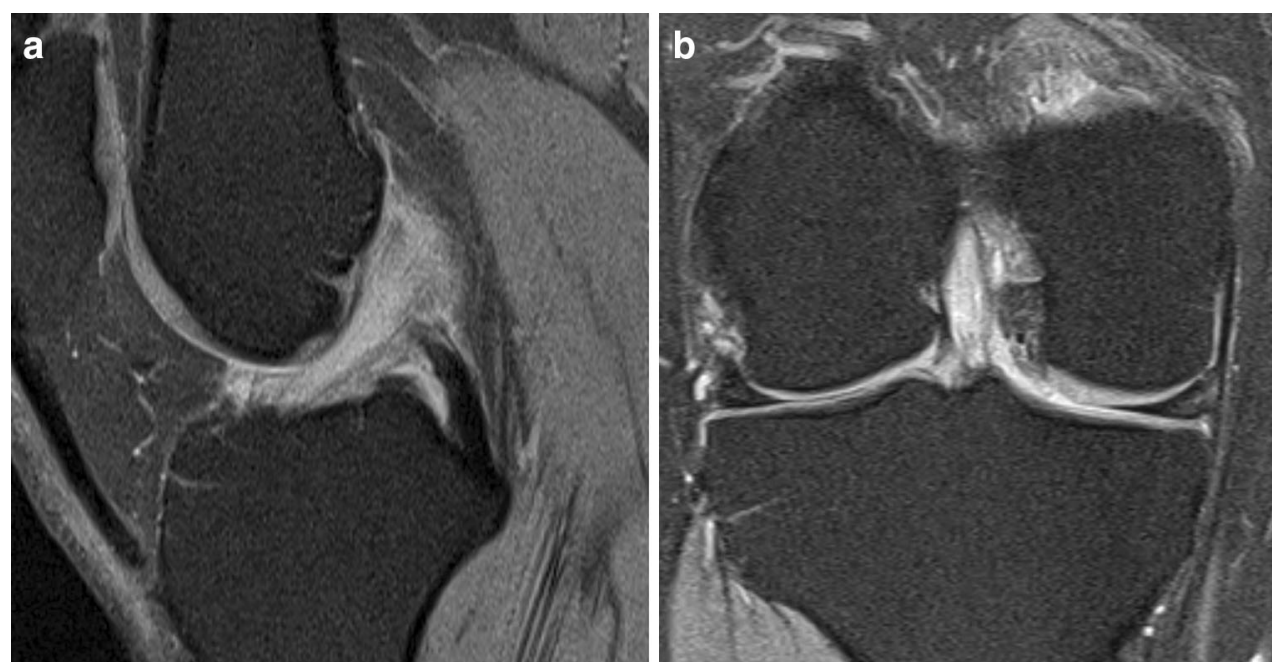

Fig. 13 a Sagittal PD-weighted and $\mathbf{b}$ axial PD-weighted fatsuppressed images of a 28-yearold professional athlete with a high-grade ACL tear at the femoral attachment (arrows). The ligament essentially maintains the contour on sagittal images, making the diagnosis more difficult. The tear can be well visualized on the axial images where the femoral attachment is better seen
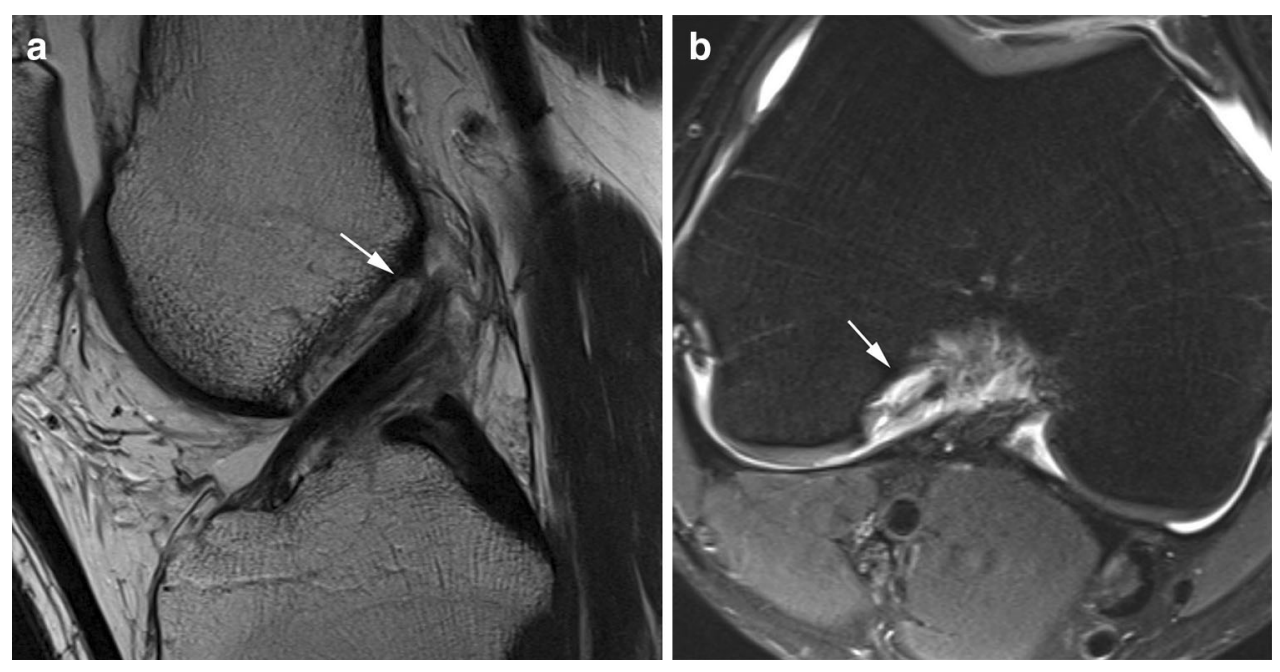

with increased signal on fluid-sensitive sequences. Furthermore, mucinous degeneration of the ACL with or without ganglion cyst formation results in diffusely increased signal within the ligament, which can be confused with a tear (Fig. 12) [36].

Partial tears or avulsion injuries, which can occur at the femoral and tibial attachments, are often better visualized on axial and coronal images, respectively (Fig. 13). Additionally, dedicated MR protocols, including imaging the knee in a slightly flexed position or acquiring images in a sagittal oblique plane, can improve the diagnostic yield of partial tears [37, 38]. When the knee is in flexion, there is improved accuracy secondary to the loss of volume averaging in the intercondylar notch. The sagittal oblique technique follows the specific course and orientation of the ACL, allowing for visualization of most of the ligament fibers in a single slice and reduced volume averaging. The sagittal oblique technique has the added advantage that the patient does not need to be repositioned.

The PCL is larger and stronger than the ACL and is rarely the only structure involved in an injury. The PCL is more likely to have a partial or chronic partial tear when compared to the ACL [39]. Whereas ACL tears often show complete disruption of the fibers, $62-77 \%$ of surgically proven PCL tears have ligamentous continuity on MR [4042]. Although there may be continuity of the ligament, the contour of the ligament may be deformed (Fig. 14) [40]. The most sensitive findings for a chronic partial tear are 
Fig. 14 Sagittal PD-weighted images show abnormal contour (arrows) of an otherwise intactappearing PCL. Confirmed near complete tear at arthroscopy
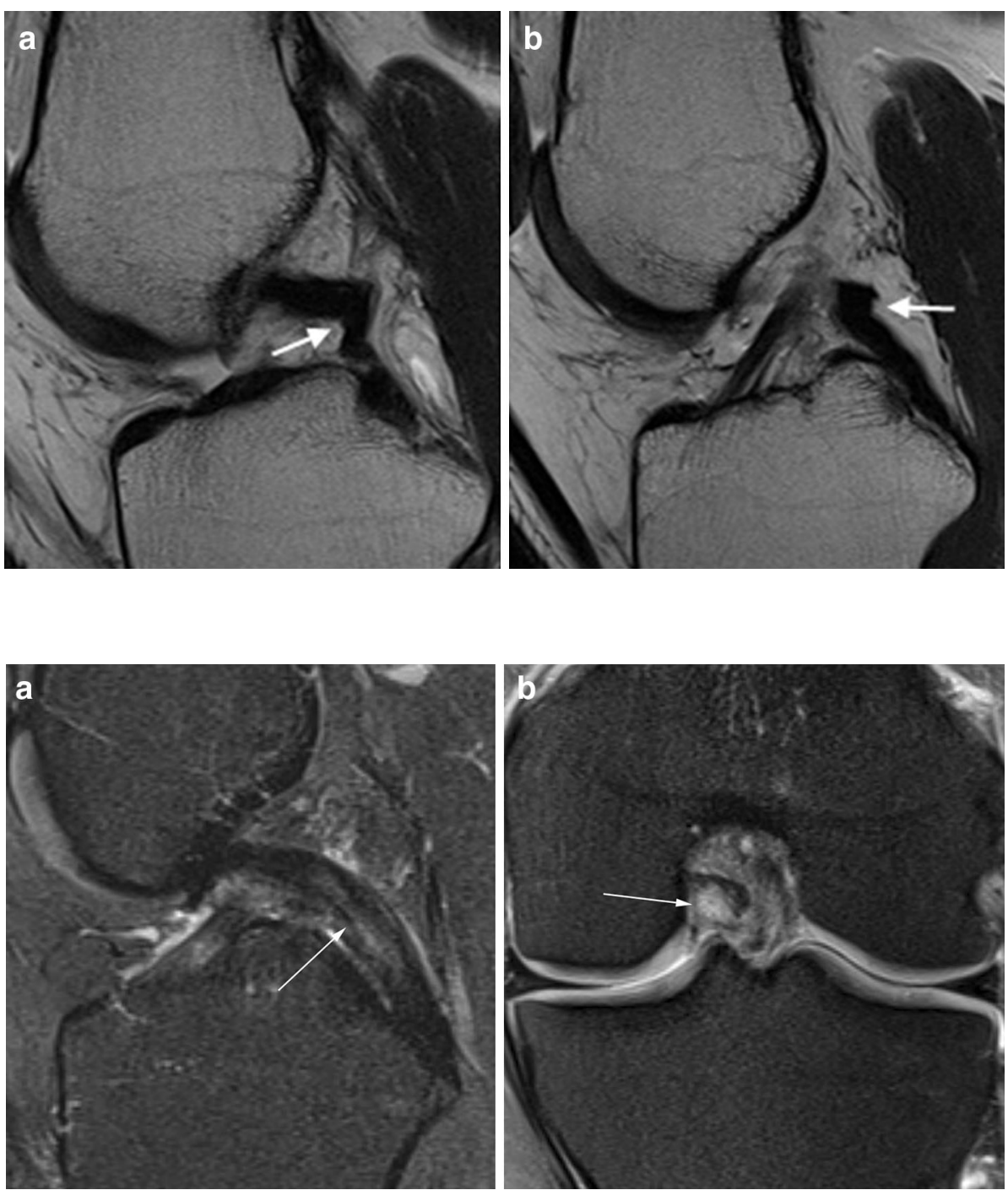

Fig. 15 Partial tear PCL. a Sagittal T2-weighted fatsuppressed and $\mathbf{b}$ coronal PDweighted fat-suppressed images show increased signal and thickening of the PCL (arrows), which maintains its normal contour increased signal on proton density sequences and thickening of the ligament (Fig. 15) [41, 43]. These findings can also be seen with mucoid degeneration of the PCL, although mucoid degeneration typically has a more "tramtrack" appearance with increased signal intensity between the peripheral rim of hypointense PCL fibers [44].

\section{Medial Collateral Ligament and Posterolateral Corner}

The MCL, made up of superficial and deep bands, is the most commonly injured ligament in the knee [45, 46]. Fortunately, the MCL has great potential for healing, and an isolated injury of the MCL can typically be managed conservatively [47]. Although $\mathrm{MR}$ is excellent at evaluating the MCL, low-grade injuries are likely overestimated as fluid and edema around the MCL or within the MCL bursa can be seen with multiple other pathologies, including medial meniscal tears and osteoarthritis [48]. This medial compartment pathology can result in bulging of the MCL with fluid deep to the MCL that is reactive and not indicative of a sprain $[46,48]$. There is also a subset of patients with deep MCL injuries located typically at the proximal femoral attachment, which may have persistent pain despite conservative therapy and may benefit from surgery (Fig. 16) [45]. The same pathology that may result in overestimation of low-grade MCL injuries can lead to under diagnosing of deep MCL tears. Another potential problem when evaluating the MCL is injuries at or near the distal tibial attachment. Standard field of view on dedicated 


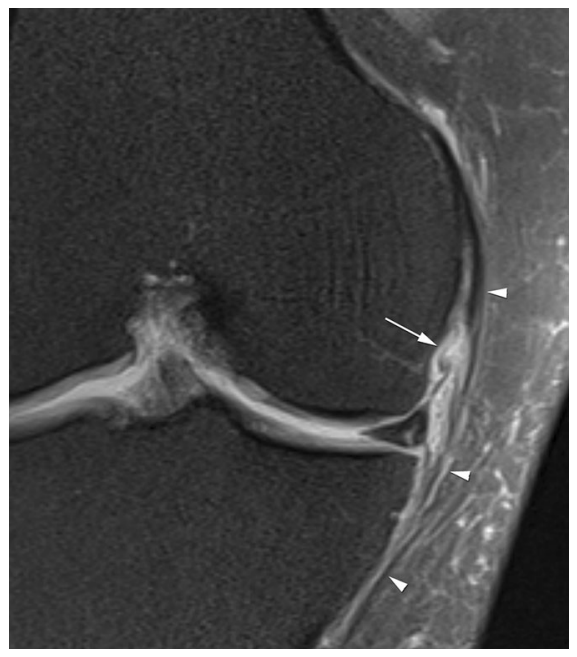

Fig. 16 A 26-year-old male with partial tear of the MCL. Coronal PD-weighted fat-suppressed images show a tear of the deep MCL fibers (arrow) along with a low-grade injury of the superficial fibers (arrowheads)

MR imaging of the knee often excludes the distal tibial attachment, and edema and fluid around the distal portion of the MCL should raise suspicion for injury and prompt additional imaging (Fig. 17).

The posterolateral corner (PLC) is a diagnostic challenge because of its complex and variable anatomy. Multiple small structures, difficult to image, can be found in the PLC. These structures are better visualized with dedicated coronal oblique images $[49,50]$. Although PLC injuries account for only $2 \%$ of acute ligament injuries of the knee, failure to treat injuries to the PLC can result in continued instability and poor surgical outcome [51, 52]. Fifteen percent of ACL reconstructions fail secondary to unrecognized
PLC injury [53]. MR performs well in the acute setting with an accuracy of $93 \%$ within 12 weeks of injury. It performs poorly when imaging is delayed with an accuracy of $26 \%$ after 12 weeks [54*0]. Additionally, imaging should be performed soon after injury, as surgical outcome is better if performed within the first 3 weeks [55]. Signal changes around the lateral collateral ligament and popliteus tendon, especially in the context of a cruciate ligament injury, should raise concern for an associated PLC injury as these rarely occur in isolation (Fig. 18) [56].

\section{Cartilage}

A meta-analysis by Zhang et al. [57] demonstrated MR to have an overall sensitivity of $75 \%$ in detecting chondral abnormalities (Fig. 19). The high number of false-negative findings is predominantly secondary to suboptimal spatial resolution and the resulting difficulty in identifying lowgrade, partial-thickness lesions [58, 59]. The in-plane spatial resolution needed to detect superficial degenerating cartilage is $0.3 \times 0.3 \mathrm{~mm}$ [60]. False-positive findings can be secondary to subcartilage lesions, such as chondrocalcinosis, misdiagnosed as cartilage damage as well as physiologic thinning of the cartilage, such as along the anterior weight-bearing surface of the lateral femoral condyle [61, 62]. False-positive chondral defects of the trochlea occur on axial images secondary to volume averaging with the prefemoral fat. When evaluating cartilage, it is important to assess multiple planes, including axial and sagittal planes for the patellofemoral compartment and coronal and sagittal planes for the tibiofemoral compartments. Additionally, the axial images can be helpful in evaluating the far posterior femoral condyles.
Fig. 17 a Coronal T2-weighted fat-suppressed images show fluid around the MCL that has a wavy appearance (arrows). b Axial PD-weighted fatsuppressed images show avulsion of the MCL distal tibial attachment as labeled
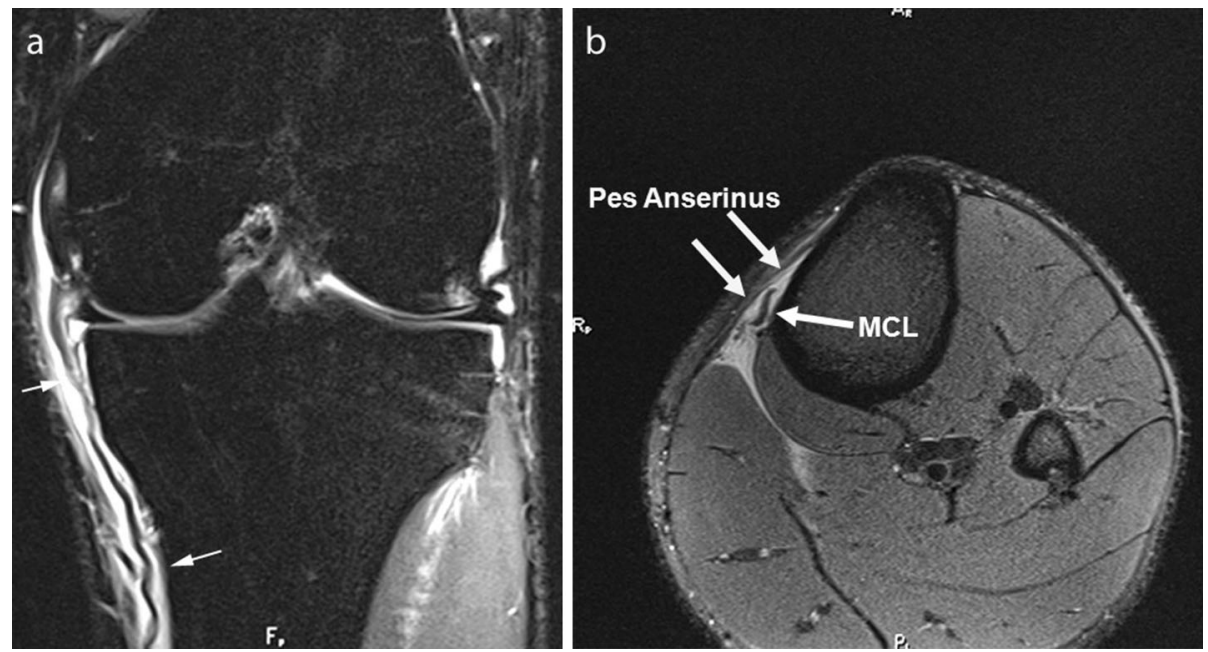

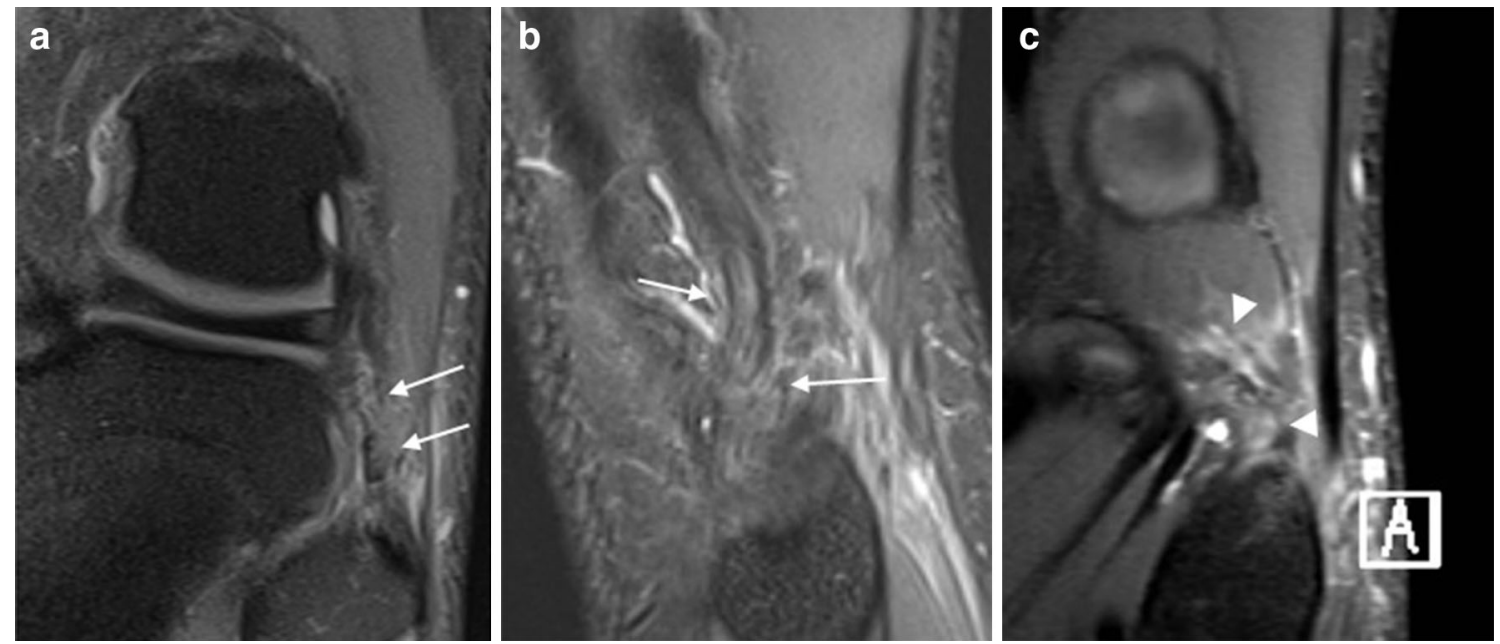

Fig. 18 a Coronal and b sagittal PD-weighted fat-suppressed images show partial tear of the fibular collateral ligament (arrows). c Coronal T2-weighted fat-suppressed image in the same patient shows a sprain of the popliteofibular ligament (arrowheads)

The current standard magnetic strength in clinical imaging is $1.5 \mathrm{~T}$. The 3-T MR with an improved signal-tonoise ratio allows for better image quality with increased spatial resolution and thinner slices within a reasonable scan time [63, 64]. However, studies have demonstrated only minimal improvement in sensitivity, specificity and accuracy at $3 \mathrm{~T}$ compared to $1.5 \mathrm{~T}[65,66]$. The sensitivity, specificity and accuracy were 69-76, 86-96 and $80-90 \%$ at $3 \mathrm{~T}$ and $60-71,78-96$ and $74-87 \%$ at $1.5 \mathrm{~T}$. Despite advancements, thin fissures, chondral flaps and shallow defects remain difficult to evaluate on MR [67]. The use of 3D cartilage sequencing instead of the standard 2D sequences in most MR knee protocols can improve performance [68•]. Delayed gadolinium-enhanced MRI of the cartilage has been used for research, but has not been used routinely in the clinical setting $[69,70]$.

\section{Maltracking, friction and impingement syndromes}

Patellofemoral maltracking can be easily overlooked if the patient has not had a patellar dislocation with a resulting typical bone contusion pattern involving the lateral femoral condyle and medial patella. A shallow trochlear groove along with lateral subluxation of the patella and patellar tilting can suggest maltracking. Edema within the superolateral aspect of Hoffa's fat has been associated with patellofemoral maltracking and fat impingement between the patellar tendon and lateral femoral condyle (Fig. 20) [71]. This theory is supported by the female predominance and association with patella alta, lateral patellar subluxation and lateral patellar tilt [72•]. Patella alta is the most consistent feature of patellar instability and maltracking. The reduced contact between the patella alta and trochlea during flexion allows for excessive lateral motion of the patella [73].

There are several fat pads located around the knee that can be a source of pain. The majority of the fat pads are distributed along the anterior aspect of the knee, including the anterior suprapatellar, posterior suprapatellar and infrapatellar (Hoffa's) fat pads. Alterations in joint mechanics secondary to trauma, repetitive microtrauma or other causes of patellofemoral instability lead to inflammation, fibrosis and degenerative changes of the anterior fat pads. This in turn causes anterior knee pain known as "fat pad impingement syndrome" [74]. This most often involves the infrapatellar fat pad with inflammatory changes and an accompanying mass effect on the patellar tendon [75, 76]. Similar findings can occur with the suprapatellar fat pads with edema and mass-like protrusion on the suprapatellar bursa [77]. A recent study demonstrated this finding in $13.8 \%$ of exams; however, it was rarely associated with anterior knee pain [78]. The pericruciate fat pad, situated between the cruciate ligaments within the intercondylar fossa, can be a source of posterior knee pain, especially in athletes. Fat pad impingement syndrome should be considered if there is edema within the fat pad and no additional intraarticular pathology is identified [79].

Iliotibial band syndrome is a common problem in long distance runners characterized by anterolateral knee pain and edema along the iliotibial tract. The reported incidence is between 1.6 and $12 \%$, making it the most common cause of lateral knee pain in runners [80]. During knee flexion, the iliotibial band goes from an anterior position relative to the lateral femoral epicondyle to a posterior position. This repetitive cyclical motion over the lateral femoral epicondyle in long distance runners presumptively leads to inflammation of the distal iliotibial band [81]. An 

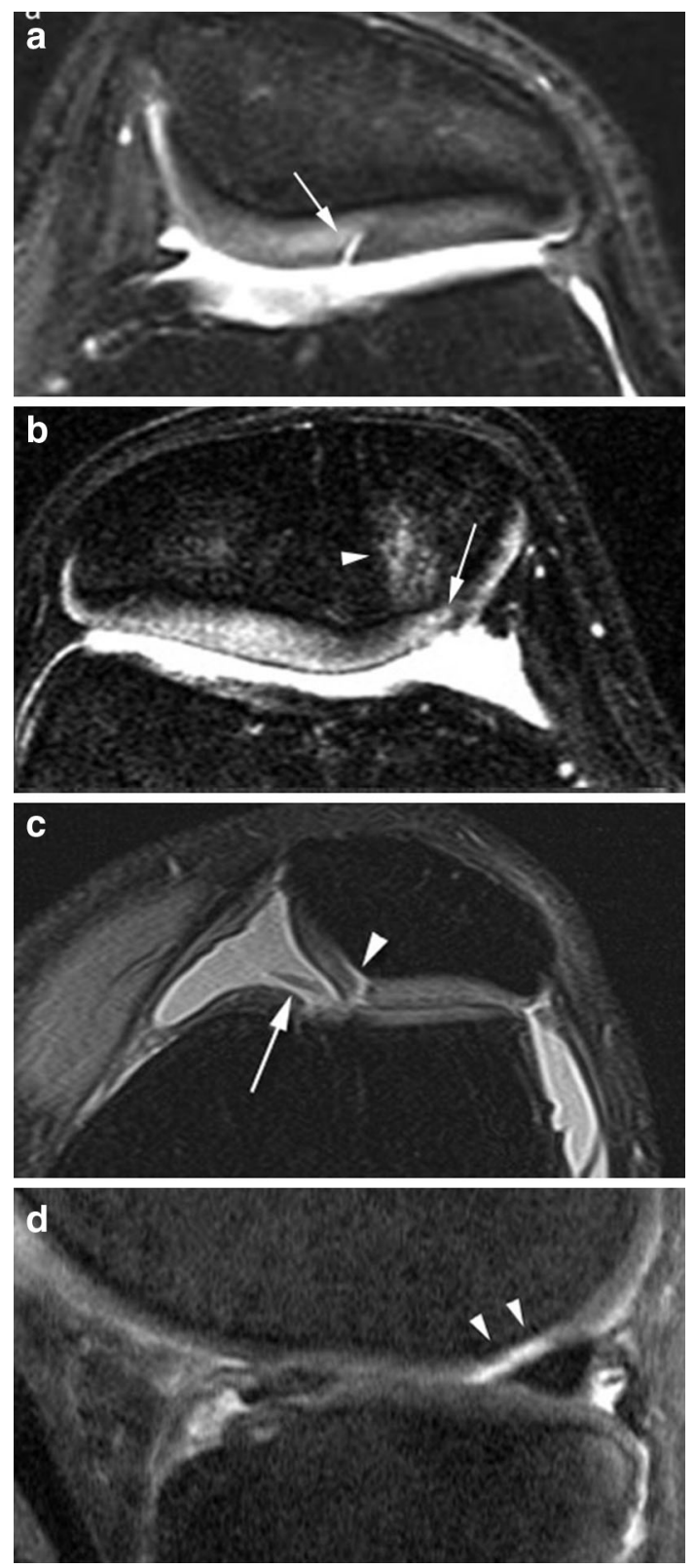

Fig. 19 Chondral lesions. a Axial PD-weighted fat-suppressed image shows a partial thickness fissure (arrow) along the lateral patellar facet. b Axial T2-weighted fat-suppressed image shows a small chondral lesion (arrow) with associated subchondral marrow changes (arrowhead). c Axial PD-weighted fat-suppressed image shows a chondral flap (arrowhead) at the medial patellar facet and a small displaced fragment (arrow). d Sagittal PD-weighted fat-suppressed image shows partial thickness chondral loss along the lateral femoral condyle (arrowheads). Modified from [90], with permission

alternative theory suggests that the iliotibial band causes compression of the highly vascular adipose tissue between the iliotibial band and the lateral femoral epicondyle resulting in a compression syndrome and not a friction syndrome as initially described [82]. Whatever the cause, MR shows high intensity signal between the iliotibial band
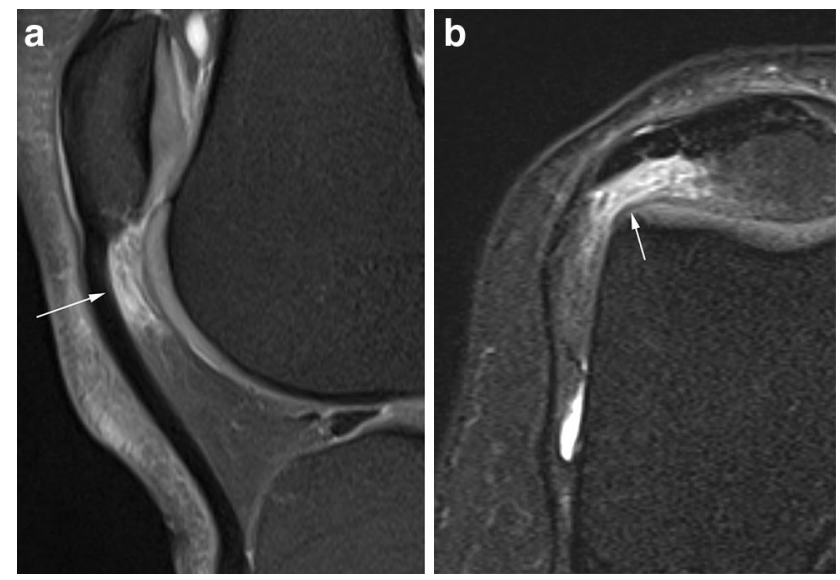

Fig. 20 a Sagittal PD-weighted fat-suppressed image and $\mathbf{b}$ axial T2weighted fat-suppressed image of a 27 -year-old female show edema in the superolateral aspect of Hoffa's fat (arrows) between the patellar tendon and lateral trochlea suggesting impingement and patellofemoral maltracking

and the lateral epicondyle along with thickening of the distal ITB (Fig. 21). Fluid within the suprapatellar bursa can be confused with iliotibial band pathology and should be distinguished on axial images.

\section{Plicae}

Plicae are folds of the redundant synovial tissue within the joint. There are four major plicae in the knee, which are often overlooked, but can be a potential source of pathology. These are identified in relation to the patella and include the medial patellar, suprapatellar, infrapatellar and lateral patellar plicae. The prevalence of plicae in the general population is $20-87 \%$ with the infrapatellar plica being the most commonly seen [83]. The medial patellar plica, which can become entrapped between the femur and patella, is the one most often associated with pain. The plica may appear thickened with increased signal on $\mathrm{T} 2$ or STIR and can cause articular cartilage wear along the patella and femoral condyle (Fig. 22) [84]. Initially, symptoms may be secondary to the inflamed plica itself. However in the later stages, as the plica becomes fibrotic and thickened, it may result in mechanical synovitis, alteration of patellofemoral mechanics as well as chondromalacia of the medial patellar facet and trochlea [85]. The infrapatellar plica, although rarely symptomatic, can also undergo fibrosis and thickening, losing its normal elasticity. This can result in impingement at the intercondylar notch with resulting pain during extension. Surgical resection of the thickened plica at arthroscopy can result in resolution of symptoms and increased range of motion [86]. Lack of awareness often leads to failure to 
Fig. 21 Iliotibial band syndrome. a Coronal PDweighted fat-suppressed and b axial T2-weighted fatsuppressed images in a 25 -yearold runner with lateral knee pain shows edema (arrows) between the iliotibial band and lateral femoral condyle
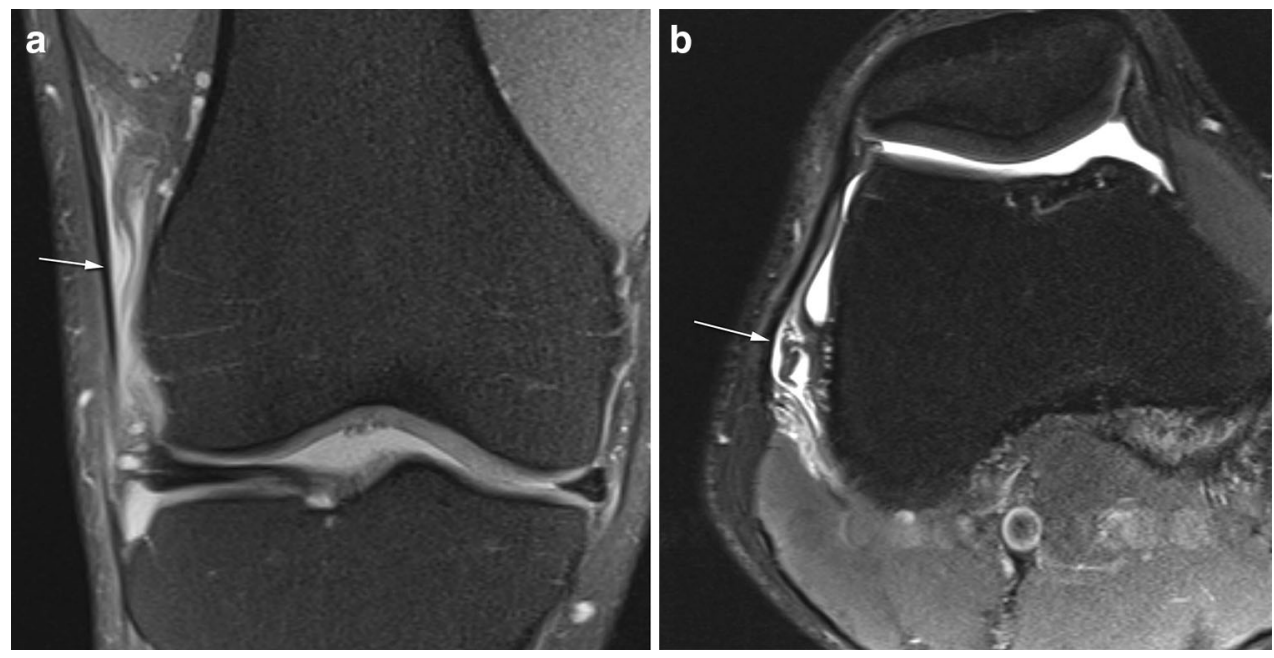

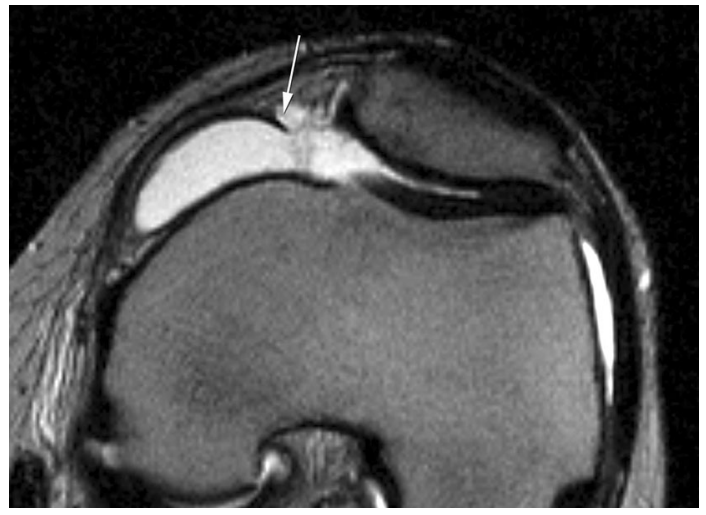

Fig. 22 A 26-year-old male with medial plica syndrome. There is a prominent medial plica (arrow) with adjacent synovitis within the suprapatellar bursa

diagnose and treat plica syndrome [87]. Though the prevalence of plica syndrome is reported to be 3.8-5.5\% during arthroscopy and MR has a reported sensitivity and specificity of 93 and $81 \%$, respectively, in diagnosing medial plica syndrome, it remains underreported at MR $[88,89]$.

\section{Conclusion}

MR remains the most accurate noninvasive diagnostic tool for the diagnosis of knee pathology. Despite this, there continue to be misinterpreted and overlooked lesions. Knowledge of normal anatomic structures and interpretive pitfalls can lead to more accurate and useful interpretation. By tailoring exams when necessary for specific pathology, such as PLC injuries and chondral lesions, we can further improve our diagnostic accuracy and help guide patient treatment.

\section{Compliance with Ethics Guidelines}

Conflict of Interest Claus Simpfendorfer and Joshua Polster have nothing to disclose.

Human and Animal Rights and Informed Consent This article does not contain any studies with human or animal subjects performed by the authors.

\section{References}

Papers of particular interest, published recently, have been highlights as:

- Of importance;

•- Of major importance

1. Turner DA, Prodromos CC, Petasnick JP, Clark JW. Acute injury of the ligaments of the knee: magnetic resonance evaluation. Radiology. 1985;154(3):717-22.

2. Maurer EJ, Kaplan PA, Dussault RG, Diduch DR, Schuett A, McCue FC, et al. Acutely injured knee: effect of MR imaging on diagnostic and therapeutic decisions. Radiology. 1997;204(3): 799-805.

3. Paxton ES, Stock MV, Brophy RH. Meniscal repair versus partial meniscectomy: a systematic review comparing reoperation rates and clinical outcomes. Arthroscopy. 2011;27(9):1275-88.

4. Tenuta JJ, Arciero RA. Arthroscopic evaluation of meniscal repairs. Factors that effect healing. Am J Sports Med. 1994;22(6):797-802.

5. Mackenzie R, Palmer CR, Lomas DJ, Dixon AK. Magnetic resonance imaging of the knee: diagnostic performance studies. Clin Radiol. 1996;51(4):251-7. 
6. Oei EH, Nikken JJ, Verstijnen AC, Ginai AZ, Hunink MGM. MR imaging of the menisci and cruciate ligaments: a systematic review. Radiology. 2003;226(3):837-48.

7. De Smet AA, Norris MA, Yandow DR, Quintana FA, Graf BK, Keene JS. MR diagnosis of meniscal tears of the knee: Importance of high signal in the meniscus that extends to the surface. AJR Am J Roentgenol. 1993;161(1):101-7.

8. Van Dyck P, Vanhoenacker FM, Lambrecht V, Wouters K, Gielen JL, Dossche L, et al. Prospective comparison of 1.5 and 3.0-T MRI for evaluating the knee menisci and ACL. J Bone Joint Surg Am. 2013;95(10):916-24.

9. Grossman JW, De Smet AA, Shinki K. Comparison of the accuracy rates of 3-T and 1.5-T MRI of the knee in the diagnosis of meniscal tear. AJR Am J Roentgenol. 2009;193(2):509-14.

10. Stoller DW, Martin C, 3rd Crues JV, Kaplan L, Mink JH. Meniscal tears: pathologic correlation with MR imaging. Radiology. 1987;163(3):731-5.

11. Takeda Y, Ikata T, Yoshida S, Takai H, Kashiwaguchi S. MRI high-signal intensity in the menisci of asymptomatic children. J Bone Joint Surg Br. 1998;80(3):463-7.

12. Cothran RL Jr, Major NM, Helms CA, Higgins LD. MR imaging of meniscal contusion in the knee. AJR Am J Roentgenol. 2001;177(5):1189-92.

13. Kaushik S, Erickson JK, Palmer WE, Winalski CS, Kilpatrick SJ, Weissman BN. Effect of chondrocalcinosis on the MR imaging of knee menisci. AJR Am J Roentgenol. 2001;177(4):905-9.

14. Shankman S, Beltran J, Melamed E, Rosenberg ZS. Anterior horn of the lateral meniscus: another potential pitfall in MR imaging of the knee. Radiology. 1997;204(1):181-4.

15. Herman LJ, Beltran J. Pitfalls in MR imaging of the knee. Radiology. 1988;167(3):775-81.

16. De Smet AA. How I diagnose meniscal tears on knee MRI. AJR Am J Roentgenol. 2012;199(3):481-99.

17. Sanders TG, Linares RC, Lawhorn KW, Tirman PF, Houser C. Oblique meniscomeniscal ligament: another potential pitfall for a meniscal tear-anatomic description and appearance at MR imaging in three cases. Radiology. 1999;213(1):213-6.

18. Harper KW, Helms CA, 3rd Lambert HS, Higgins LD. Radial meniscal tears: significance, incidence, and MR appearance. AJR Am J Roentgenol. 2005;185(6):1429-34.

19. De Smet AA, Graf BK. Meniscal tears missed on MR imaging: relationship to meniscal tear patterns and anterior cruciate ligament tears. AJR Am J Roentgenol. 1994;162(4):905-11.

20. De Smet AA, Mukherjee R. Clinical, MRI, and arthroscopic findings associated with failure to diagnose a lateral meniscal tear on knee MRI. AJR Am J Roentgenol. 2008;190(1):22-6.

21. Fischer SP, Fox JM, Del Pizzo W, Friedman MJ, Snyder SJ, Ferkel RD. Accuracy of diagnoses from magnetic resonance imaging of the knee. A multi-center analysis of one thousand and fourteen patients. J Bone Joint Surg Am. 1991;73(1):2-10.

22. Brody JM, Lin HM, Hulstyn MJ, Tung GA. Lateral meniscus root tear and meniscus extrusion with anterior cruciate ligament tear. Radiology. 2006;239(3):805-10.

23. Ozkoc G, Circi E, Gonc U, Irgit K, Pourbagher A, Tandogan RN. Radial tears in the root of the posterior horn of the medial meniscus. Knee Surg Sports Traumatol Arthrosc. 2008;16(9):849-54.

24. Davis KW, Rosas HG, Graf BK. Magnetic resonance imaging and arthroscopic appearance of the menisci of the knee. Clin Sports Med. 2013;32(3):449-75.

25. - Gokalp G, Nas OF, Demirag B, Yazici Z, Savci G. Contribution of thin-slice $(1 \mathrm{~mm})$ axial proton density MR images for identification and classification of meniscal tears: correlative study with arthroscopy. Br J Radiol. 2012;85(1018):e871-8. Study demonstrating increased sensitivity, specificity and classification of meniscal tears using thin-slice axial PDW MRI.
26. Tarhan NC, Chung CB, Mohana-Borges AV, Hughes T, Resnick D. Meniscal tears: role of axial MRI alone and in combination with other imaging planes. AJR Am J Roentgenol. 2004;183(1):9-15.

27. McKnight A, Southgate J, Price A, Ostlere S. Meniscal tears with displaced fragments: common patterns on magnetic resonance imaging. Skeletal Radiol. 2010;39(3):279-83.

28. Lecas LK, Helms CA, Kosarek FJ, Garret WE. Inferiorly displaced flap tears of the medial meniscus: MR appearance and clinical significance. AJR Am J Roentgenol. 2000;174(1):161-4.

29. De Maeseneer M, Shahabpour M, Vanderdood K, Van Roy F, Osteaux M. Medial meniscocapsular separation: MR imaging criteria and diagnostic pitfalls. Eur J Radiol. 2002;41(3):242-52.

30. Rubin DA, Britton CA, Towers JD, Harner CD. Are MR imaging signs of meniscocapsular separation valid? Radiology. 1996;201(3):829-36.

31. De Maeseneer M, Shahabpour M, Van Roy F, Goossens A, De Ridder F, Clarijs J, et al. MR imaging of the medial collateral ligament bursa: findings in patients and anatomic data derived from cadavers. AJR Am J Roentgenol. 2001;177(4):911-7.

32. Petersen W, Zantop T. Partial rupture of the anterior cruciate ligament. Arthroscopy. 2006;22(11):1143-5.

33. Panisset JC, Duraffour H, Vasconcelos W, Colombet P, Javois C, Potel JF, et al. Clinical, radiological and arthroscopic analysis of the ACL tear. A prospective study of 418 cases. Rev Chir Orthop Reparatrice Appar Mot. 2008;94(8 Suppl):362-8.

34. Noyes FR, Mooar LA, Moorman CT 3rd, McGinniss GH. Partial tears of the anterior cruciate ligament. Progression to complete ligament deficiency. J Bone Joint Surg Br. 1989;71(5):825-33.

35. DeFranco MJ, Bach BR Jr. A comprehensive review of partial anterior cruciate ligament tears. J Bone Joint Surg Am. 2009;91(1):198-208.

36. McIntyre J, Moelleken S, Tirman P. Mucoid degeneration of the anterior cruciate ligament mistaken for ligamentous tears. Skeletal Radiol. 2001;30(6):312-5.

37. Pereira ER, Ryu KN, Ahn JM, Kayser F, Bielecki D, Resnick D. Evaluation of the anterior cruciate ligament of the knee: comparison between partial flexion true sagittal and extension sagittal oblique positions during MR imaging. Clin Radiol. 1998;53(8):574-8.

38. Nenezic D, Kocijancic I. The value of the sagittal-oblique MRI technique for injuries of the anterior cruciate ligament in the knee. Radiol Oncol. 2013;47(1):19-25.

39. Sanders TG, Miller MD. A systematic approach to magnetic resonance imaging interpretation of sports medicine injuries of the knee. Am J Sports Med. 2005;33(1):131-48.

40. Jung YB, Jung HJ, Yang JJ, Yang DL, Lee YS, Song IS, et al. Characterization of spontaneous healing of chronic posterior cruciate ligament injury: analysis of instability and magnetic resonance imaging. J Magn Reson Imaging. 2008;27(6):1336-40.

41. Rodriguez W Jr, Vinson EN, Helms CA, Toth AP. MRI appearance of posterior cruciate ligament tears. AJR Am J Roentgenol. 2008;191(4):1031.

42. Tewes DP, Fritts HM, Fields RD, Quick DC, Buss DD. Chronically injured posterior cruciate ligament: magnetic resonance imaging. Clin Orthop Relat Res. 1997;(335):224-32.

43. Sonin AH, Fitzgerald SW, Hoff FL, Friedman H, Bresler ME. MR imaging of the posterior cruciate ligament: normal, abnormal, and associated injury patterns. Radiographics. 1995;15(3):551-61.

44. McMonagle JS, Helms CA, Garrett WE Jr, Vinson EN. Tramtrack appearance of the posterior cruciate ligament (PCL): correlations with mucoid degeneration, ligamentous stability, and differentiation from PCL tears. AJR Am J Roentgenol. 2013;201(2):394-9.

45. Narvani A, Mahmud T, Lavelle J, Williams A. Injury to the proximal deep medial collateral ligament: a problematical subgroup of injuries. J Bone Joint Surg Br. 2010;92(7):949-53. 
46. De Maeseneer M, Shahabpour M, Pouders C. MRI spectrum of medial collateral ligament injuries and pitfalls in diagnosis. JBRBTR. 2010;93(2):97-103.

47. Jacobson KE, Chi FS. Evaluation and treatment of medial collateral ligament and medial-sided injuries of the knee. Sports Med Arthrosc. 2006;14(2):58-66.

48. Wen DY, Propeck T, Kane SM, Godbee MT, Rall KL. MRI description of knee medial collateral ligament abnormalities in the absence of trauma: edema related to osteoarthritis and medial meniscal tears. Magn Reson Imaging. 2007;25(2):209-14.

49. Yu JS, Salonen DC, Hodler J, Haghighi P, Trudell D, Resnick D. Posterolateral aspect of the knee: improved MR imaging with a coronal oblique technique. Radiology. 1996;198(1):199-204.

50. Bolog N, Hodler J. MR imaging of the posterolateral corner of the knee. Skeletal Radiol. 2007;36(8):715-28.

51. Larsen MW, Toth A. Examination of posterolateral corner injuries. J Knee Surg. 2005;18(2):146-50.

52. Geiger D, Chang E, Pathria M, Chung CB. Posterolateral and posteromedial corner injuries of the knee. Radiol Clin North Am. 2013;51(3):413-32.

53. O'Brien SJ, Warren RF, Pavlov H, Panariello R, Wickiewicz TL. Reconstruction of the chronically insufficient anterior cruciate ligament with the central third of the patellar ligament. J Bone Joint Surg Am. 1991;73(2):278-86.

54. • Pacheco RJ, Ayre CA, Bollen SR. Posterolateral corner injuries of the knee: a serious injury commonly missed. J Bone Joint Surg Br. 2011;93(2):194-7. Retrospective study highlighting the delay in diagnosis of posterolateral corner injuries and the benefit of MRI when performed in the acute setting.

55. Baker CL Jr, Norwood LA, Hughston JC. Acute combined posterior cruciate and posterolateral instability of the knee. Am J Sports Med. 1984;12(3):204-8.

56. Brown TR, Quinn SF, Wensel JP, Kim JH, Demlow T. Diagnosis of popliteus injuries with MR imaging. Skeletal Radiol. 1995;24(7):511-4.

57. Zhang M, Min Z, Rana N, Liu H. Accuracy of magnetic resonance imaging in grading knee chondral defects. Arthroscopy. 2013;29(2):349-56.

58. Kijowski R, Blankenbaker DG, Woods MA, Shinki K, De Smet AA, Reeder SB. 3.0-T evaluation of knee cartilage by using three-dimensional IDEAL GRASS imaging: comparison with fast spin-echo imaging. Radiology. 2010;255(1):117-27.

59. Von Engelhardt LV, Lahner M, Klussmann A, Bouillon B, David A, Haage P, et al. Arthroscopy vs. MRI for a detailed assessment of cartilage disease in osteoarthritis: diagnostic value of MRI in clinical practice. BMC Musculoskelet Disord. 2010;11:75.

60. Rubenstein JD, Li JG, Majumdar S, Henkelman RM. Image resolution and signal-to-noise ratio requirements for MR imaging of degenerative cartilage. AJR Am J Roentgenol. 1997;169(4):1089-96.

61. Nikolaou VS, Chronopoulos E, Savvidou C, Plessas S, Giannoudis $\mathrm{P}$, Efstathopoulos $\mathrm{N}$, et al. MRI efficacy in diagnosing internal lesions of the knee: a retrospective analysis. J Trauma Manag Outcomes. 2008;2(1):4.

62. Yoshioka H, Stevens K, Genovese M, Dillingham MF, Lang P. Articular cartilage of knee: normal patterns at MR imaging that mimic disease in healthy subjects and patients with osteoarthritis. Radiology. 2004;231(1):31-8.

63. Ramnath RR. 3 T MR imaging of the musculoskeletal system (Part I): considerations, coils, and challenges. Magn Reson Imaging Clin N Am. 2006;14(1):27-40.

64. Wong S, Steinbach L, Zhao J, Stehling C, Ma CB, Link TM. Comparative study of imaging at $3.0 \mathrm{~T}$ versus $1.5 \mathrm{~T}$ of the knee. Skeletal Radiol. 2009;38(8):761-9.

65. Van Dyck P, Kenis C, Vanhoenacker FM, Lambrecht V, Wouters $\mathrm{K}$, Gielen JL, et al. Comparison of 1.5- and 3-T MR imaging for evaluating the articular cartilage of the knee. Knee Surg Sports Traumatol Arthrosc. 2013; doi:10.1007/s00167-013-2704-8.

66. Kijowski R, Blankenbaker DG, Davis KW, Shinki K, Kaplan LD, De Smet AA. Comparison of 1.5- and 3.0-T MR imaging for evaluating the articular cartilage of the knee joint. Radiology. 2009;250(3):839-48.

67. Von Engelhardt LV, Kraft CN, Pennekamp PH, Schild HH, Schmitz A, von Falkenhausen M. The evaluation of articular cartilage lesions of the knee with a 3-Tesla magnet. Arthroscopy. 2007;23(5):496-502.

68. - Kijowski R, Blankenbaker DG, Woods M, Del Rio AM, De Smet AA, Reeder SB. Clinical usefulness of adding 3D cartilage imaging sequences to a routine knee MR protocol. AJR Am J Roentgenol. 2011;196(1):159-67. Prospective study demonstrating improved diagnostic performance of MRI in detecting cartilage lesions when adding a $3 D$ sequences to the routine $M R$ protocol.

69. Bittersohl B, Hosalkar HS, Haamberg T, Kim YJ, Werlen S, Siebenrock KA, et al. Reproducibility of dGEMRIC in assessment of hip joint cartilage: a prospective study. J Magn Reson Imaging. 2009;30(1):224-8.

70. Multanen J, Rauvala E, Lammentausta E, Ojala R, Kiviranta I, Hakkinen A, et al. Reproducibility of imaging human knee cartilage by delayed gadolinium-enhanced MRI of cartilage (dGEMRIC) at 1.5 tesla. Osteoarthritis Cartilage. 2009; 17(5):559-64.

71. Chung CB, Skaf A, Roger B, Campos J, Stump X, Resnick D. Patellar tendon-lateral femoral condyle friction syndrome: MR imaging in 42 patients. Skeletal Radiol. 2001;30(12):694-7.

72. - Jibri Z, Martin D, Mansour R, Kamath S. The association of infrapatellar fat pad oedema with patellar maltracking: a casecontrol study. Skeletal Radiol. 2012;41(8):925-31. Study demonstrating association of edema within the superolateral portion of Hoffa's fat pad and patellar maltracking.

73. Simmons E Jr, Cameron JC. Patella alta and recurrent dislocation of the patella. Clin Orthop Relat Res. 1992;(274):265-9.

74. Faletti C, De Stefano N, Giudice G, Larciprete M. Knee impingement syndromes. Eur J Radiol. 1998;27(Suppl 1):S60-9.

75. Saddik D, McNally EG, Richardson M. MRI of Hoffa's fat pad. Skeletal Radiol. 2004;33(8):433-44.

76. Emad Y, Ragab Y. Liposynovitis prepatellaris in athletic runner (Hoffa's syndrome): case report and review of the literature. Clin Rheumatol. 2007;26(7):1201-3.

77. Shabshin N, Schweitzer ME, Morrison WB. Quadriceps fat pad edema: significance on magnetic resonance images of the knee. Skeletal Radiol. 2006;35(5):269-74.

78. Tsavalas N, Karantanas AH. Suprapatellar fat-pad mass effect: MRI findings and correlation with anterior knee pain. AJR Am J Roentgenol. 2013;200(3):W291-6.

79. Skaf AY, Filho HG, Dirim B, Wangwinyuvirat M, Trudell D, Haghighi P, et al. Pericruciate fat pad of the knee: anatomy and pericruciate fat pad inflammation: cadaveric and clinical study emphasizing MR imaging. Skeletal Radiol. 2012;41(12):1591-6.

80. Strauss EJ, Kim S, Calcei JG, Park D. Iliotibial band syndrome: evaluation and management. J Am Acad Orthop Surg. 2011;19(12):728-36.

81. Orchard JW, Fricker PA, Abud AT, Mason BR. Biomechanics of iliotibial band friction syndrome in runners. Am J Sports Med. 1996;24(3):375-9.

82. Fairclough J, Hayashi K, Toumi H, Lyons K, Bydder G, Phillips $\mathrm{N}$, et al. Is iliotibial band syndrome really a friction syndrome? J Sci Med Sport. 2007;10(2):74-6; discussion 77-8.

83. Demirag B, Ozturk C, Karakayali M. Symptomatic infrapatellar plica. Knee Surg Sports Traumatol Arthrosc. 2006;14(2):156-60.

84. Garcia-Valtuille R, Abascal F, Cerezal L, Garcia-Valtuille A, Pereda T, Canga A, et al. Anatomy and MR imaging appearances 
of synovial plicae of the knee. Radiographics. 2002;22(4): 775-84.

85. Schindler OS. 'The sneaky plica' revisited: morphology, pathophysiology and treatment of synovial plicae of the knee. Knee Surg Sports Traumatol Arthrosc. 2013;. doi:10.1007/s00167-0132368-4.

86. Kim SJ, Kim JY, Lee JW. Pathologic infrapatellar plica. Arthroscopy. 2002;18(5):E25.

87. Broom MJ, Fulkerson JP. The plica syndrome: a new perspective. Orthop Clin North Am. 1986;17(2):279-81.
88. Dorchak JD, Barrack RL, Kneisl JS, Alexander AH. Arthroscopic treatment of symptomatic synovial plica of the knee. Long-term followup. Am J Sports Med. 1991;19(5):503-7.

89. Nakanishi K, Inoue M, Ishida T, Murakami T, Tsuda K, Ikezoe J, et al. MR evaluation of mediopatellar plica. Acta Radiol. 1996;37(4):567-71.

90. Azer NM, Winalski CS, Minas T. MR imaging for surgical planning and postoperative assessment in early osteoarthritis. Radiol Clin North Am. 2004;42(1):43-60. 